\title{
TOURISM PRODUCT QUALITY PERCEPTIONS AND BIG SPENDERS' TRAVEL INTENTIONS IN MALAYSIA: A COMPARATIVE STUDY OF SOUTHEAST ASIAN AND MIDDLE EASTERN COUNTRIES
}

\author{
Zaliha Zainuddin', Mazni Saad ${ }^{2}$ \& Mohd Hanafi Azman Ong ${ }^{3}$ \\ ${ }^{1}$ Faculty of Business, Economics and Social Development, Universiti Malaysia Terengganu \\ ${ }^{2}$ Department of Tourism, Kulliyyah of Languages and Management, \\ International Islamic University Malaysia, \\ ${ }^{3}$ Faculty of Computer and Mathematical Sciences, Universiti Teknologi MARA (Johor) \\ (zaliha.z@umt.edu.my, maznisaad@iium.edu.my, napieong@uitm.edu.my)
}

\begin{abstract}
Tourism is the second-largest economic driver of the Malaysian economy. This paper aims to examine the mediating role of perceived tourism product quality (TPQ) in Malaysia on electronic word-of-mouth (eWOM) and the intent to travel to Southeast Asia (SEA) and the Middle East.

Two-fold objectives were developed which are to investigate the significant difference of the perception between SEA and Middle East countries on Malaysian's tourism products quality and to examine the mediating role of perceived tourism products quality in Malaysia towards eWOM and travelling intentions of SEA and the Middle East. The questionnaire that was used to collect the data used in this study was designed with tourists from SEA and the Middle East who have been to Malaysia in mind. The questionnaire was designed for online distribution using Google Forms. The study processed 92 responses from Middle Eastern tourists and had another 79 respondents from SEA. The data sets and responses were analysed using Partial Least Squares Structural Equation Modelling (PLS-SEM) and MANOVA techniques. The findings show a significant mediating effect of perceived TPQ towards the eWOM and revisit intentions of tourists. Besides, comparison analysis shows that SEA tourists are more likely to revisit Malaysia than the Middle East, the same as for the finding of eWOM and perceived TPQ. TPQ has a mediating impact on eWOM and the intention to revisit both geographical locations. The findings of this study are expected to positively affect stakeholders, especially the State Tourism, Tourism Board, and tourism industry players.
\end{abstract}

KEYWORDS: eWOM, Tourism Product Quality, Big Spender Tourists, South East Asia, Middle East

\section{PURPOSE AND BACKGROUND}

Fundamentally, this study examines the travel intentions of large-scale travelers from Southeast Asia (SEA) and the Middle East to Malaysia. This study aims to assess the eWOM of international tourists, the perceived quality of TPQ, and revisit intentions. Two-fold objectives were developed:

(1) To investigate the significant difference of the perception between SEA and Middle East countries on Malaysian's tourism products quality.

2) To examine the mediating role of perceived tourism products quality in Malaysia towards eWOM and travelling intentions of SEA and the Middle East. 


\section{METHODOLOGY}

Given the study aims to consider the perception in SEA and Middle Eastern countries on Malaysia's tourism product quality and to examine the mediating role of the perceived product quality of tourism offerings in Malaysia towards eWOM and the intention to travel to SEA or the Middle East, a quantitative analysis and survey methodology were employed in this study, since it aims to explore the effect of perceived tourism product quality with Electronic Word-of-Mouth (eWOM) and revisit intentions being mediator variables using quantitative measurements (i.e. structured questionnaire).

A total of 171 respondents being tourist groups from South East Asia (i.e., SEA) and the Middle East (i.e., ME) were selected using purposive convenience sampling. It employed the use of electronic data collection methods so as to ensure all questions asked in the structured questionnaire were answered by the respondent.

Statistical analysis was then done using Structural Equation Modeling with Partial Least Squares (i.e., PLS-SEM) estimation multivariate data techniques since the sample size for this study can be considered relatively small). PLS-SEM was considered the optimal statistical data analysis method since it allowed the researchers to test the indicators used for measuring targeted constructs based on convergent validity and discriminant validity.

In addition, the significance test in the PLS-SEM analysis was computed using a bootstrapping method, which can be considered a more robust method as compared to the conventional t-test method, 5000 replications of the samples were computed for getting reliable results for empirical t-statistics and bias correction (i.e., BCa) bootstrap. For comparative purposes, an independent t-test was used for accessing the different average values of the targeted variables between two tourists' group.

\section{FINDINGS}

The findings show a significant mediating effect of perceived TPQ toward the relationship of eWOM and revisit intention. In addition, comparison analysis shows that SEA tourists are more likely to revisit Malaysia as compared to the Middle East, same as for the finding of eWOM and perceived TPQ. TPQ has a mediating impact on eWOM and revisit intentions for both geographical areas.

This mediating study will advance the idea the role of perceived TPQ towards eWOM and travel intentions of big spenders in Malaysia: A comparative study on SEA and Middle East countries, in this study, is expected to intervene in the governments policy in harnessing the competitiveness of Malaysia's tourism industry in line with the National Tourism Policy 2020-2030.

The study has answered in its investigation and significant difference of the perception between SEA and Middle East countries on Malaysian's tourism products quality and finding of mediating roles of perceived TPQ in Malaysia towards electronic-word-of-mouth (eWOM) and the intent to travel to SEA and or the Middle East.

\section{CONCLUSION}

If the average level of Electronic Word-of-Mouth was increase, basically it will increase the average level of Perceived Tourism Product Quality simultaneously, hence indirectly the Perceived Tourism Product Quality will increase the average revisit the country. 
In the same way, an increase in the level of Electronic Word-of-Mouth will directly increase the level of intentions to revisit the country. The comparative analysis shows that, tourists from South East Asia are more likely to have a better perception and leave a favourable review by Electronic Word-of-Mouth, and have higher level of Perceived Tourism Product Quality and consequently more intent to revisit as compare to Middle Eastern tourists. The analysis indicated that, if the average level of Electronic Word-of-Mouth was increased, it will increase the average level of Perceived Tourism Product Quality simultaneously, which will increase the average level of intentions to revisit.

In the same way, an increase in the level of Electronic Word-of-Mouth will directly improve the average level of intentions to revisit. The comparative analysis shows that, tourists from South East Asia are more likely to give a better review by way of Electronic Word-of-Mouth, and have a higher level of Perceived Tourism Product Quality and intent to revisit as compare to Middle Eastern tourists.

\section{CONTRIBUTION/PRACTICAL IMPLICATIONS}

The findings of this research will contribute to the current literature on customers' attitudes and behaviours towards the average level of perceived TPQ between SEA tourist group and the Middle East tourist group, where tourists from SEA are more likely to give a better perceived TPQ perception. TPQ has a mediating impact on eWOM and revisit intention for both geographical areas.

Particularly, it will contribute to the current knowledge on SEA and Middle East tourists' attitudes and behaviours toward Malaysia's product quality. The practical contribution of this research will help marketers in creating marketing campaigns that will attract SEA and Middle East's Big Spenders markets. The understanding of customers' attitudes and behaviours towards eWOM and Malaysia tourism product quality will help marketers in the tourism and hospitality industry in Malaysia to improve their marketing performance, which will reflect positively on the industry.

\section{REFERENCES}

Abbasi, G. A., Kumaravelu, J., Goh, Y.-N., \& Dara Singh, K. S. (2021). Understanding the intention to revisit a destination by expanding the theory of planned behaviour (TPB). Spanish Journal of Marketing ESIC, ahead-of-p (ahead-of-print). https://doi.org/10.1108/sjme-12-2019-0109

Hair, J. F., Hult, G. T. M., Ringle, C. M., \& Sarstedt, M. (2017). A primer on partial least squares structural equation modeling (PLS-SEM) (2nd ed.). Thousand Oaks: Sage Publications

Zainuddin, Z., Mohd Zahari, M. S., Mohd Radzi. S., \& Mohd Hanafiah, M. H. (2020). Tourism destination competitiveness, The Langkawi Island perspective (pp. 13-19). Penerbit UMT. 